\title{
Prostate Cancer Vaccines, Fibrin and Selenium: A Conceptual Review
}

\author{
Boguslaw Lipinski* \\ Joslin Diabetes Center, Harvard Medical School, Boston, MA 02215, USA
}

\begin{abstract}
Cancer immunotherapy is based on a concept that persistent presence of tumors in cancer patients is a result of immunological breakdown and/or downregulation of the tumor immunogenecity. In view of their limited efficacies, it can be argued that the problem lies not in a particular vaccine, but in tumors themselves. It is known that the rapidly dividing cells express free sulfhydryl groups on the membrane surfaces that can undergo disulfide exchange reactions with thiols of other biomolecules. Under physiological conditions sulfhydryl groups of circulating plasma proteins are engaged in the intramolecular disulfide bridges and are not available for the exchange. However, in neoplastic diseases, particularly in the prostate cancer, such an exchange reaction takes place between fibrinogen and human serum albumin resulting in the formation of a fibrin-like aggregate. A characteristic feature of such an insoluble aggregate is its remarkable resistance to proteolytic degradation not only by plasmin but by active lysosomal proteases as well. As a consequence prostate cancer cells accrue a protective coat of 'self ' proteins that is not recognizable by the body's immune system. Moreover, even if some of the unmasked tumor antigens do elicit immune response, the fibrin coat is refractive to degradation by the proteases released by natural killer cells. Consequently, in order to achieve successful immunotherapy the protective barrier of disulfide crosslinked fibrinogen-albumin complex has to be first eliminated. This can be done by the pretreatment with four-valent sodium selenite but not with other chemical forms of selenium. Selenite oxidizes thiols of the tumor cell membranes to disulfides thus making them unavailable for the exchange reaction with partially reduced plasma proteins. Although selenite is known to be toxic to humans when given orally, its body's concentration can be safely increased by the parenteral administration. In conclusion, specific chemical properties of sodium selenite warrant its careful evaluation as a potential improvement of the efficacy of prostate cancer vaccines thus contributing to the reduction of mortality of this deadly form of cancer
\end{abstract}

Keywords: Prostate cancer, immunotherapy, fibrinogen, albumin, disulfide exchange.

\section{INTRODUCTION}

An idea of immune-based therapies of cancer was initiated over 100 years ago by William B. Coley who had first observed tumor regression in inoperable cancer patients after injection with pyogenic bacterial extracts [1]. However, because of lack of understanding of a mechanism of action of this type of therapy, Coley's findings have been ignored for many years. Only more recently new data became available indicating that certain viruses and bacteria can be used as anti-cancer agents $[2,3]$. Moreover, it was demonstrated that exotoxins of group A streptococci can function as 'superantigens' capable of activating $\mathrm{T}$ cells followed by their massive infiltration of the tumor [4]. Despite positive results obtained in some cases [5], the limited effectiveness of cancer vaccines is still a puzzle and thus brings to our attention Paul Ehrlich's idea of the importance of immune surveillance rather than the activity of natural killer (NK) cells. More recently, an alternative explanation was offered by which immunogenic tumors avoid destruction by inducing T-cell tolerance [6].

\section{ROLE OF FIBRIN(OGEN) IN CANCER IMMUNO- THERAPY}

Yet there is another, albeit not generally recognized reason why tumors may avoid immune recognition and destruc-

*Address correspondence to this author at the Joslin Diabetes Center, Harvard Medical School, Boston, MA 02215, USA; Tel: 617-732-2693; Fax: 617-732-2667; E-mail: boguslaw_lipinski@joslin.harvard.edu tion. This concept is based on the role of fibrin that forms a protective coat on the surface of tumor cells making them "invisible" for the immune surveillance system. Fibrin is normally formed from fibrinogen by the action of enzyme thrombin generated as a result of blood coagulation activation. The function of fibrin in hemostasis is to form a clot at the site of vessel wall injury that has to be gradually removed by the fibrinolytic enzymes to ensure proper wound healing. Intravascular fibrinolysis is achieved by the release of plasminogen activators, specifically tissue type (tPA) that generate plasmin on a solid phase of fibrin clots [7]. However, under certain pathologic conditions fibrin is not effectively removed leading to atheroslerosis that was argued to be a result of free radical modification of fibrin(ogen) [8]. Certain neurological diseases are also known to be associated with increased production of oxygen centered free radicals $[9,10]$ and the concurrent deposition of fibrin(ogen)reactive antigen in the patient's brains [11]. The presence of insoluble fibrin(ogen)-albumin complex in Alzheimer's brain tissue is another example of the resistance of such a complexes to immune and/or fibrinolytic elimination [12].

It is well known that the persistent presence of fibrin matrix in prostate cancer tissue is associated with a continuous release of tPA [13]. Yet despite such a high fibrinolytic activity in the stroma of prostate cancer, fibrin lysis is not achieved thus creating a state of permanent thrombosis [14]. Association of thrombosis with cancer was already observed over one hundred years ago by Trousseau [15] and later on confirmed by numerous investigators [16-20]. The most 
plausible explanation for the occurrence of fibrin in cancer tissues is inhibition of fibrinolysis reported by several researchers [21-23]. Importance of fibrinolytic inhibition in cancer is further supported by the finding that the treatment of mice with two potent inhibitors (Aprotinin and EACA) have significantly increased lung B16F10 melanoma metastasis [24].

There is, however, no readily available explanation why fibrin in cancer tissues is resistant to fibrinolytic degradation. One of the causes could be that the properties of such fibrins are different that those of normal hemostatic clots. Thus, it has been reported that fibrin deposits continue to be formed in patients anticoagulated with warfarin [25] suggesting an alternative mechanism of their formation. This notion was confirmed by the observation that the fibrin-like material is formed in cancer tissue without thrombin generation [26]. It has been suggested that the enzyme-induced coagulation does not contribute to progression of adenocarcinoma of the prostate [27]. Therefore the question arises about a possible mechanism of fibrin formation in neoplastic tissues other than the classical activation of blood coagulation. The most likely explanation is the formation of fibrin-like insoluble aggregate ("neofibe") by the action of hydroxyl radicals on fibrinogen [28]. A characteristic feature of free radicalmodified human fibrinogen is its remarkable resistance to fibrinolytic degradation [29]. Very recently evidence has accumulated showing that chronic inflammation plays an important role in several degenerative diseases such as cancer, diabetes and cardiovascular disorders [30, 31]. Chronic inflammation is, in turn, associated with the excessive production of free radicals [32] that facilitates cellular malignancy and proliferation [33]. According to Ames [34] chronic infection and inflammation contribute to approximately one-quarter of all cancer cases worldwide. Another important factor in cancer pathogenesis is iron overload known to contribute to the generation of the most biologically active hydroxyl radicals [35-37]. Iron is contained in red meat and thus its excessive consumption may explain the positive association with advanced prostate cancer [38], as well as other forms of cancer [39-45].

A very important fact should be noted namely that cancer tissue, in addition to fibrin-like material, contains insoluble forms of human serum albumin (HSA) [46] shown to be associated with fibrinolytic inhibition [47]. In connection with this the following fact is of extreme importance for the concept presented in this paper. Under certain conditions fibrinogen can form a complex with HSA by virtue of a disulfide exchange reaction [48]. Normally, practically all cysteine residues in fibrinogen are engaged in the intramolecular disulfide bridges that hold together alpha, beta and gamma polypetide chains of this protein. However, in cases of congenital fibrinogen abnormalities single nucleotide base changes result in Ser-->Cys or Arg-->Cys substitutions that endows fibrinogen with an extra cysteine residue [49, 50]. Such a modification of fibrinogen makes it vulnerable to the disulfide exchange reaction and the formation of a complex with human serum albumin. These type of complexes can be formed in vitro by exposure of human plasma to hydroxyl radicals generated in the presence of iron and/or copper ions as well as by the limited reduction with a dithiol reagent [51]. In both cases the insoluble fibrinogen-albumin complex is resistant to degradation not only by plasmin, but by active proteases such as trypsin or chymotrypsin. This phenomenon may explain the protection of fetus as a "foreign" antigen in pregnancy by forming fibrinolytically resistant feto-maternal barrier as demonstrated by Wasiutynski et al. [52].

On the basis of these findings, a concept was put forward according to which the reducing condition of the cancer environment causes the expression of extracellular cysteine residues [53] and/or generation of hydroxyl radicals that, in turn, catalyze the formation of insoluble fibrinogen- HSA complexes. Such complexes when deposited on the surfaces of cancer cells form a protease-resistant coat that is presented as "self " to the innate and/or extrinsic cellular immune systems. Therefore, rather an unsettling conclusion can be drawn that no matter how potent is a given vaccine under the in vitro conditions, its in vivo efficacy will always depend on their ability to overcome the intricate cancer camouflage.

\section{POTENTIAL SIGNIFICANCE OF SELENIUM}

In view of the above-mentioned mechanisms, the resistance of prostate and other forms of cancer to immunotherapy was suggested to be linked to selenium [54], a ubiquitous metalloid essential in human nutrition. There is a number of important publications on the preventive and therapeutic role selenium in cancer [55-62]. Because of a wide range concentration of selenium in soil, its daily intake may greatly vary depending on a geographical location and diet. Yet despite a plethora of publications on this subject there is still a considerable confusion as to which form and dose of selenium are clinically effective [63-65]. This problem was also very recently addressed in a comprehensive review by Schrauzer [66]. Apparently not all forms of selenium are equally effective, very likely due to their different chemical reactivity [67-70]. Thus, only four-valent sodium selenite but not six-valent selenate is redox active and can react with polythiols to oxidize them to their corresponding disulfides. On the other hand, organically bound selenium, as in selenomethionine, was shown to be ineffective in the rat model of prostate cancer [71]. Selenite is also known to directly activate NK cells [72], to trigger apoptosis in prostate cancer cells [73], and to contribute to the to eradication of the multidrug resistant acute myeloid leukemia [74]. Moreover, supplementation of selenium was shown to enhance chemotherapeutic effect of Taxol and Doxorubicin in these cells beyond that seen with the chemotherapeutic drugs alone [75]. The recent findings indicating that the anticancer action of selenium involves transactivation of p53 [76] suggest that selenite may be useful not only for the prevention but also for treatment of human prostate cancer [77, 78]. It has recently been argued that, in light of a sufficient scientific evidence [79-82], selenium should be introduced into clinical trials of cancer therapy [83].

The proposed mechanism of anticancer action of sodium selenite $\left(\mathrm{Na}_{2} \mathrm{SeO}_{3}\right)$ is based on its affinity to sulhydryl (-SH) groups of proteins $(\mathrm{P})$ on the surface of tumor cells converting them to intra-molecular disulfides according to the following reaction:

$\mathrm{P}-[\mathrm{SH}]_{2}+\mathrm{Na}_{2} \mathrm{SeO}_{3}---->\mathrm{P}-\mathrm{S}-\mathrm{S}-\mathrm{P}+\mathrm{NaOH}+\mathrm{SeO}$ 


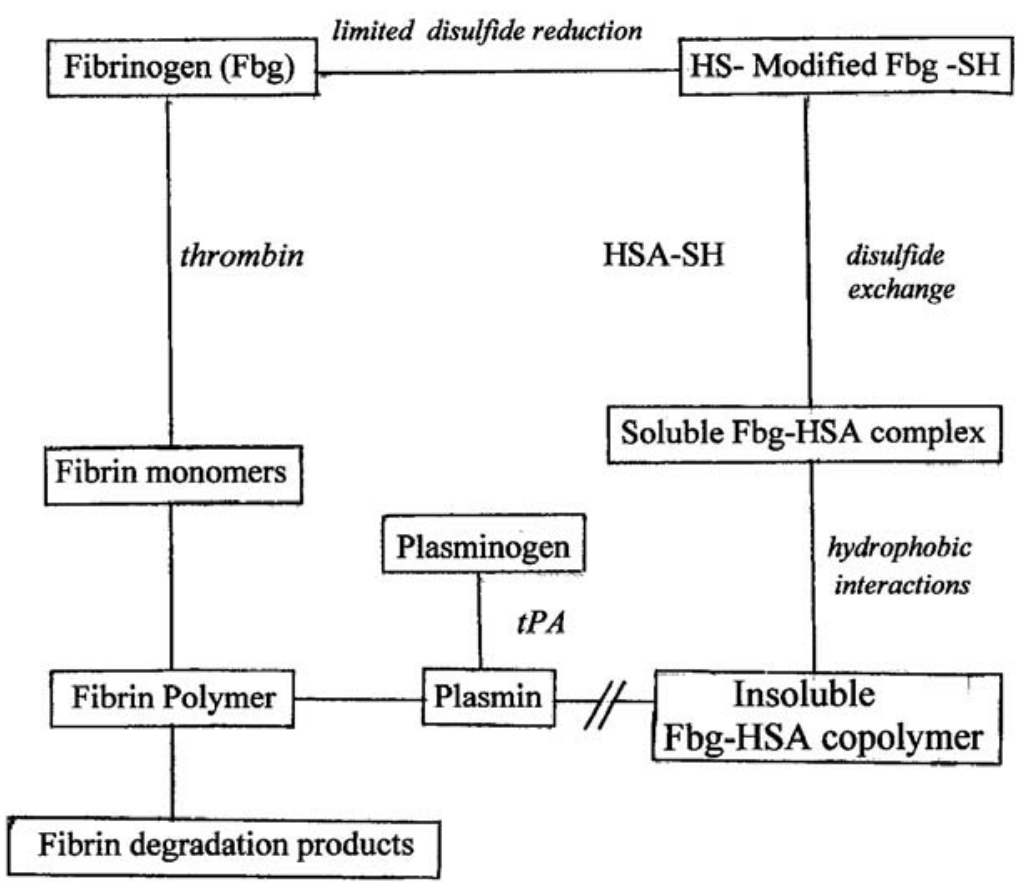

Fig. (1). Schematic representation of the physiologic conversion of fibrinogen to fibrin with thrombin, and its proteolytic degradation with plasmin. Under reducing conditions of prostate cancer stroma some of the intramolecular disulfides become converted to free sulfhydryls (-SH), which subsequently undergo disulfide exchange with those of human serum albumin (HSA). The resulting soluble complex interacts with hydrophobic regions on cancer cell membranes and thus renders the complex insoluble and resistant to proteolytic degradation.

In this way protein polysulfhydryls on cell walls become unavailable for the formation of inter-molecular disulfide bridges between fibrinogen and albumin molecules thus preventing their deposition on the cell surfaces [84]. Since both these proteins belong to the 'self ' family of molecules, the cellular immune system does not recognize them and consequently saves them from destruction. But even if the tertiary structure of a modified fibrinogen-albumin complex differs somewhat from their native states and elicits immune response, proteolytic enzymes released from NK cells cannot degrade it because of its highly hydrophobic nature similar to that of amyloid polypetide [85]. In the case of prostate cancer the first line of attack is the release of massive amounts of tPA that is not consumed in the process of plasminogen activation because of altered surface properties of the modified fibrin(ogen) similar to the thrombolytic resistance [86]. This phenomenon explains why prostate cancer is generally believed to be associated with activated fibrinolysis, which in fact represents only an increased potential for fibrinolysis.

\section{CONCLUSION}

In conclusion, the most important issue in the immune therapy of prostate cancer seems to be resistance of tumor cells to a complete eradication by various types of vaccines. It is suggested in this review that the problem is not with vaccine themselves, but with their inability to recognize prostate tumor as a foreign body. This is due to the formation of a protective coat composed of 'self ' fibrinogen-albumin complex that is not recognizable by the cellular immune system and is also refractory to proteolytic degradation. A putative mechanism of the protective coat formation versus normal fibrin clot generation is presented in Fig. (1).
Therefore, in order to achieve successful prostate tumor elimination a protective coat should be prevented from the deposition around the cancer cells. This can be achieved by the administration of sodium selenite that blocks sulfhydryl groups, and thus prevent disulfide exchange to occur between fibrinogen and albumin, and their deposition on the surface of cancer cells. To obtain desirable results with the use of emerging vaccine cancer therapies optimal concentrations of selenite have to be determined in human subjects. In view of a potential toxicity of oral sodium selenite at higher concentrations (over $600 \mathrm{mcg} / \mathrm{day}$ ), alternative parenteral routes of administration, such as intravenous, transdermal and/or transcutaneous should be investigated as demonstrated in patients with septic shock [87]. Finally, it should be noted that there are several studies in animal models, which support the concept of vaccine immunotherapy against prostate cancer $[88,89]$.

\section{REFERENCES}

[1] Wieman B, Starnes CO. Coley's toxins, tumor necrosis factor and cancer research: a historical perspective. Pharmacol Ther 1994; 64: 529-564.

[2] Csatary LI. Viruses in the treatment of cancer. Lancet 1971; 2: 825.

[3] Kirchner HH, Anton P, Atzpodien J. Adjuvant treatment ocally advanced renal cancer with autologus virus-modified tumor vaccines. World J Urol 1995; 13: 171-173.

[4] Dohlsten M, Lando PA, Bjork P. Immunotherapy of human colon cancer by antibody-targeted superantigens. Cancer Immunol Immunother 1995; 41: 162-168.

[5] Rosenberg SA. Develoment of effective immunotherapy for the treatment of patients with cancer. J Am Coll Surg 2004; 198: 685696.

[6] Willimsky G, Blankenstein T. Sporadic immunogenic tumours avoid destruction by inducing T-cell tolerance. Nature 2005; 437 : 141-146. 
[7] Lipinski B, Nowak A, Gurewich V. Fibrinolysis versus fibrinogenolysis of man: resistance of fibrinogen to breakdown by fibrinolytic activity induced by venous occlusion. Experientia 1974; 30; 84-86.

[8] Lipinski B, Lipinska I. Free radical-induced modification of human fibrinogen: Implication for arteriosclerosis. In: arteriosclerosis, risk factors, diagnosis and treatment. Kostner M, Kostner KM, Eds, 2002.

[9] Summers WK. Alzheimer's disease, oxidative injury and cytokines. J Alzheimers Dis 2004; 6: 651-657.

[10] Markesbery WR, Carney JM. Oxidative alterations in Alzheimer's disease. Brain Pathol 1999; 9: 131-146.

[11] Roher AE, Kokjohn TA, Beach TG. An association with great implications: vascular pathology and Alzheimer disease. Alzheimer Dis Assoc Disord 2006; 20: 73-75.

[12] Lipinski B, Sajdel-Sulkowska EM. New insight into Alzheimer's disease: demonstration of fibrin(ogen)-serum albumin insoluble deposits in brain tissue. Alzheimer Dis Assoc Disord 2006; 20: 324-326.

[13] Strickland DK, de Serrano VS, Chan SY, Pollard M, Castellino FJ. Purification and properties of plasminogen activator from cultured rat prostate adenocarcinoma cells. Biochemistry 1983; 22: 444-449.

[14] Dworak HF, Senger DR, Dvorak AM. Fibrin as component of the tumor stroma: origins and biological significance. Cancer Metastasis Rev 1983; $2: 41-73$.

[15] Trousseau A. Phlegmasia Alba Dolen. Clinique Medicale del'Hotel-Dieu de Paris.1865; 3: 654.

[16] Goodnight SH. Bleeding and intravascular clotting in malignancy: a review. Ann NY Acad Sci USA 1974; 230: 271-288.

[17] Lee SY, Park LO, Suk S-H. Role of fibrinogen covalently associated with cell membrane in blood-borne tumor colony formation of murine mammary carcinoma cells. Oncology 2000; 5: 238-244.

[18] Fibrin in human tumors. Hiramoto R, Bernecky J, Jurandowski J, Pressman D. Cancer Res 1960; 20: 592-593.

[19] Kierluf P, Godal HC. Fibrinaemia and multiple thrombi in pancreatic carcinoma. Scand J Haematol 1972; 9: 370-376.

[20] Laki K. Fibrinogen and metastases. J Med 1974; 5: 32-37.

[21] Kwaan HC, Lo R, McFadzean AJS. Antifibrinolytic activity in primary carcinoma of the liver. Clin Sci 1969; 18: 251-261

[22] Farbiszewski R, Rzeczycki W, Worowski K, Glowinski S. The arginine content of fibrin clots and fibrinolysis in neoplastic diseases. Neoplasma 1973; 20: 203-208.

[23] Nagy B, Ban J, Brdar B. Fibrinolysis associated with human neoplasia: production of plasminogen activators by human tumours. Int J Cancer 1977; 19: 614-620.

[24] Kirstein JM, Graham KC, Mackenzie LT, et al. Effect of antifibrinolytic therapy on experimental melanoma metastasis. Clin Exp Metastasis 2009; 26: 121-131.

[25] Thomes RD. Oral anticoagulat therapy of human cancer. J Med 1974; 5: 83-91.

[26] Constantini V, Zacharski LR, Memoli VA, Kisiel W, Kudryk BJ, Rousseau S. Fibrinogen deposition without thrombin generation in primary human breast cancer tissue. Cancer Res 1991; 51: 349-351.

[27] Wojtukiewicz MZ, Zacharski LR, Memoli VA, et al. Fibrin formation on vessel walls in hyperplasia and malignant prostate tissue. Cancer 1991; 67: 1377-1383.

[28] Marx G, Chevion M. Fibrinogen coagulation without thrombin: reaction with vitamin C and copper(II). Thromb Res 1985; 40: 1118.

[29] Lipinski B. Evidence in support of a concept of reductive stress. Br J Nutr 2002; 87: 93-94.

[30] Allavena P, Sica A, Solinas G, Porta C, Mantovanii A. The inflammatory micro environment in tumor progression: the role of tumor-associated macrophages. Crit Rev Oncol Hematol 2008; 66: $1-9$.

[31] Khansari N, Shakiba Y, Mahmoudi M. Chronic inflammation and oxidative stress as a major cause of age-related diseases and cancer. Recent Pat Inflamm Allergy Drug Discov 2009; 3: 73-80.

[32] Hold GL, El-Omar ME. Genetic aspects of inflammation and cancer. Biochem J 2008; 410: 225-235.

[33] Cook JA, Gius D, Wink DA, Krishna MC, Russo A, Mitchell JB. Oxidative stress, redox, and the tumor microenvironment. Semin Radiat Oncol 2004; 14: 259-266.
[34] Ames BN, Gold LS, Willet WC. The cause and prevention of cancer. Proc Natl Acad Sci USA 1995; 92: 5258-5265.

[35] Reizenstein P. Iron, free radicals and cancer: a review. Med Oncol Tumor Pharmacother 1991; 8: 229-233.

[36] Sahu SC. Dietary iron and cancer: a review. Environ Carcino Ecotox Revs 1992; C10: 205-237.

[37] Huang $X$. Iron overload and the association with cancer risk in humans: evidence for iron as a carcinogenic metal. Mutat Res 2003; 533: 153-171.

[38] Sinha R, Park Y, Graubard BI, et al. Meat and meat-related compounds and risk of prostate cancer in a large prospective cohort study in the United States. Am J Epidemiol 2009; 170: 1165-1177.

[39] Bae YJ, Yeon JY, Sung CJ, Kim HS, Sung MK. Dietary intake and serum levels of iron in relation to oxidative stress in breast cancer patients. J Clin Biochem Nutr 2009; 45: 355-360.

[40] Ferrucci LM, Cross Aj, Graubard BI, Brinton LA, McCarthy CA, Ziegler RG, Ma X, Mayne ST, Sinha R. Intake of meat and iron and the risk of breast cancer in the prostate,lung, colorectal and ovarian cancer screening trial. Br J Cancer 2009; 101: 178-184.

[41] Norat T, Lukanova A, Ferrari P, Riboli E. Meat consumption and colorectal cancer risk; dose-response meta-analysis of epidemiological studies. Int J Cancer 2002; 98: 241-246.

[42] Kwiatkowski JL. Oral iron chelators. Hematol Oncol Clin North Am 2010; 24: 229-248.

[43] Rodrigues L, Teixeira J, Schmitt F, Paulsson M, Mansson HL. Lactoferrin and cancer disease prevention. Crit Rev Food Sci Nutr 2009; 49: 203-217.

[44] Toyokuni S. Role of iron in carcinogenesis: cancer as a ferrotoxic disease. Cancer Sci 2009; 100: 9-16.

[45] Zacharski LR, Chow BK, Howes PS. et al. Decreased cancer risk after iron reduction in patients with peripheral arterial disease: results from a randomized trial. J Natl Cancer Inst 2008; 100: 9961002.

[46] Soreide J, Lea OA, Kvinnsland S. Cytosol albumin content in operable breast cancer. Acta Oncol 1991; 30: 797-802

[47] Rockwell WB, Ehrlich HP. Fibrinolysis inhibition in human burn blister fluid. J Burn Care Rehabil. 1990; 11: 1-6.

[48] Lipinski B. In vitro preparation and partial characterization of a novel complex of human fibrinogen with albumin. J Prot Chem 1995; 14: 259-262.

[49] Steinmann C, Bogli C, Jungo M. et al. A new substitution, gamma 358Ser-->Cys in fibrinogen Milano. Blood 1994; 84: 1874-1880.

[50] Koopman J, Haverkate F, Grimbergen J. et al. Molecular basis for fibrinogen Dusart (A alpha 554Arg-->Cys) associated with abnormal fibrinogen polymerization and thrombophilia. J Clin Invest 1993; 91: 1637-1643.

[51] Lipinski B, Egyud LG. Thiol-induced crosslinking of human blood proteins: Implications for tumor immunity. Bioorg Med Chem Lett 1992; 2: 919-924.

[52] Wasiutynski A, Wiczynski GM, Morton M, Koperski L, Gornicka B, Ziarkiewicz-Wroblewska B. Fibrinogen/fibrin and albumin colocalize on the surface of placental villi a novel element of feto-maternal barrier? Ann Diagn Paediatr Pathol 2002; 6: 125129.

[53] Skalska J, Brookes PS, Nadtochiy SM, et al. Modulation of cell surface protein free thiols: a potential novel mechanism of the sesquiterpene lactne parthenolide. PLoS One 2009; 4: e8115.

[54] Lipinski B. Re: Science peels the onion of selenium effects on prostate carcinogenesis. J Natl Cancr Inst 2004; 96: 1640.

[55] Jung HJ, Seo YR. Current issues of selenium in cancer chemoprevention. Biofactors 2010; 36: 153-158

[56] Jackson MI, Combs GF, Jr. Selenium and anticarcinogenesis: Underlying mechanisms. Curr Opin Clin Nutr Metab Care 2008; 11: 718-726

[57] Micke O, Schomburg L, Buentzel J, Kisters K, Muecke R. Selenium in oncology: from chemistry to clinics. Molecules 2009; 14: 3975-3988

[58] Spallholtz JE. On the nature of selenium toxicity and cancerostatic activity. Free Radic Biol Med 1994; 17: 45-64.

[59] Koyama H. Selenium enrichment of broccoli sprout extract increases chemosnesitivity and apoptosis of $\mathrm{LNCaP}$ prostate cancer cells. BMC Cancer 2009; 9: 414

[60] Whanger PD. Selenium and its relationship to cancer: an update. $\mathrm{Br}$ J Nutr 2004; 91: 11-18. 
[61] Facompre N, El-Bayoumy K. Potential stages for prostate cancer prevention with selenium: implication for cancer survivors. Cancer Res 2009; 69: 2699-2703.

[62] Rayman MP. Selenium in cancer prevention: a review of the evidence and mechanism of action. Proc Nutr Soc 2005; 64: 527542 .

[63] Bahr K, Freher I, Kohrle J. Selenium supplementation by selenium yeast and sodium selenite. J Lab Med 1999; 23: 594-599.

[64] Ip C, Thompson HJ, Zhu Z, Ganther HE. In vitro and in vivo studies of methylseleninic acid: evidence that a monomethylated selenium metabolite is critical for cancer chemoprevention. Cancer Res 2000; 60: 2882-2886.

[65] Li GX, Lee HJ, Wang Z, et al. Superior in vivo inhibitory efficacy of methylseleninic acid against human prostate cancer over selenomethionine or selenite. Carcinogenesis 2008; 29: 1005-1012.

[66] Schrauzer GN, Surai PF. Selenium in human and animal nutrition: resolved and unresolved issues. A partly historical treatise in commemoration of the fiftieth anniversary of the discovery of the biological essentiality of selenium. Crit Rev Biotechnol 2009; 29: 2-9.

[67] Wang L, Bonorden MJL, Li G, et al. Methyl selenium compounds inhibit prostate carcinogenesis in the transgenic adenocarcinoma of mouse prostate model with survival benefit. Cancer Prev Res (Phila Pa) 2009; 2: 484-495

[68] Abdulah R, Miyazaki K, Nakazawa M, Koyama H. Chemical form of selenium for cancer prevention. J Trace Elem Med Biol 2005; 19: 141-150.

[69] Bandura L, Drukala J, Wolnicka-Glubisz A, Bjornstedt M, Korodoha W. Differential effect of selenite and selenate on human melanocytes, keratinocytes and melanoma cells. Biochem Cell Biol 2005; 83: 196-211.

[70] Burk RF, Norsworthy BK, Hill KE, Motley AK, Byrne DW. Effets of chemical form of selenium on plasma biomarkers in high-dose human supplementation trail. Cancer Epidemiol Biomarkers Prev 2006; 15: 804-810.

[71] McCormick DL, Rao KV, Johnson WD, Boslnd MC, Lubet RA, Steele VE. Null activity of selenium and vitamin $\mathrm{E}$ as a cancer chemopreventive agents in the rat prostate. Cancer Prev Res (Phila Pa). 2010,3: 381-392.

[72] Kiremidjian-Schumacher L, Roy M, Wishe HI, Cohen MW, Stotzky G. Supplementation with selenium augments the function of natural killer cells. Biol Trace Element Res 1996; 52: 227239.

[73] Sarveswaran S, Liroff J, Zhou Z, Nikitin AY, Ghosh J. Selenite triggers rapid transcriptional actvation of $\mathrm{p} 5$, and $\mathrm{p} 53$-mediated apoptosis in prostate cancer cells: Implications for the treatment of early-stage prostate cancer. Int J Oncol 2010; 36: 1419-1428.

[74] Olm E, Johnsson-Videsater K, Ribera-Cortada I, et al. Selenite is a potent cytotoxic agent for human primary AML cells. Cancer Lett 2009; 282: 116-123.
[75] Vadgama JV, Wu, Shen D, Hsia S, Block J. Effect of selenium in combination with Adriamycin or Taxol on several different cancer cells. Anticancer Res 2000; 20: 1391-1414.

[76] Hu H, Jiang C, Schuster T, Li GX, Daniel PT, Lu J. Inorganic selenium sensitizes prostate cancer cells to TRAIL-induced apoptosis through superoxide/p53/Bax-mediated activation of mitochondrion pathway. Mol Cancer Ther 2006; 5: 1873-1882.

[77] Sonpavde G, Slavin KM, Spencer DM, Levitt JM. Emerging vacine therapy approaches for prostate cancer. Rev Urol 2010;12: 25-34.

[78] Abdulah R, Farried A, Kobayashi K, et al. Selenium enrichment of broccoli sprout extract increases chemosensitivity and apoptosis of LNCaP prostate cancer cells. BMC Cancer 2009; 9: 414-419.

[79] Dong Y, Lee SO, Zhang H, Marshall J, Gao AC, Ip C. Prostate specific antigen expression is down-regulated by selenium through disruption of androgen receptor signaling. Cancer Res 2004; 64(1): 19-22.

[80] Cho SD, Jiang C, Malewicz B, et al. Methyl selenium metabolites decrease prostate-specific antigen expression by inducing protein degradation and suppressing androgen-stimulated transcription. Mol Cancer Ther 2004; 3: 605-11.

[81] Corcoran NM, Najdovska M, Costello AJ. Inorganic selenium retards progression of experimental hormone refractory prostate cancer. J Urology 2004; 171: 907-910.

[82] Zhong W, Oberley TD. Redox mediated effects of selenium on apoptosis and cell cycle in the LNCaP human prostate cancer cell line. Cancer Res 2001; 61: 7071-7078.

[83] Bhattacharya RS, Husbeck B, Feldman D, Knox SJ. Selenite treatment inhibits LAPC-4 tumor growth and prostate-specific antigen secretion in a xenograft model of human prostate cancer. Int J Radiat Oncol Biol Phys 2008; 72: 935-940.

[84] Lipinski B, Egyud LG. Resistance of cancer cells to immune recognition and killing. Med Hypotheses 2000; 54: 456-460.

[85] Badman MK, Pryce RA, Charge SBP, Morris JF, Clark A. Fibrillar islet amyloid polypeptide (amylin) is internalised by macrophages but resists proteolytic degradation. Cell Tissue Res 1998; 291: 285 294.

[86] Lipinski B. Modification of fibrin structure as a possible cause of thrombolytic resistance. J Thromb Thrombolysis 2010; 29: 296-298.

[87] Forceville X, Laviolle B, Annane D, et al. Effects of high doses of selenium, as sodium selenite, in septic shock: a placebo-controlled, randomized, double-blind, phase II study. Crit Care 2007; 11: R73.

[88] Garcia-Hermandez Mde L, Gray A, Huby B, Klinger OJ, Kast WM. Prostate stem cell antigen vaccination induces a long-term protective immune response against cancer in the absence of immunity. Cancer Res 2008; 68: 861-869.

[89] Kim S, Lee JB, Lee GK, Chang J. Vaccination with recombinant adenoviruses expressing prostate-specific antigens is effective in eliciting CTL and suppresses tumor growth in the experimental prostate cancer. Prostate 2009; 69: 938-948. 